\title{
Study proposed on integrity of published data
}

Washington. A member of the recently created US Commission on Research Integrity last week suggested that a confidential study be carried out to check the correspondence between raw data and those appearing in published papers, in order to determine the extent of scientific misconduct.

The idea of such a cross-check was first put forward in 1989 by Desmond Rennie, professor of medicine at the University of California, San Francisco, and a commission member. He made the proposal in an article in the Journal of the American Medical Association, of which he is a deputy editor.

At a meeting of the commission in Washington DC, Kristina Gunsalus, vicechancellor for research at the University of Illinois at Urbana-Champaign and another member, said that she was prepared to draw up the new proposal in order to "take the heat off Rennie", acknowledging that his idea had been "met with howls of protest".

The idea of such a study was supported by Kenneth Ryan, chairman of the commission, whose creation was mandated by Congress in last year's National Institutes of Health (NIH) Reauthorization Act. "If everyone was told when they submitted a paper that their data might be requested confidentially, I would hope that it would be obvious that they would agree," Ryan said later.

Gunsalus claims that a study of the integrity of published data would not be intended as an attack on scientists. But she points out that there is no hard data to support the scientific establishment's frequent assertion that there is little misconduct in science.

Congress' decision to require NIH to set up the commission was prompted by frustration with the way in which allegations of scientific misconduct have been treated and concern that the NIH's Office of Research Integrity (ORI), which investigates allegations of misconduct, has not been working as well as Congress had hoped.

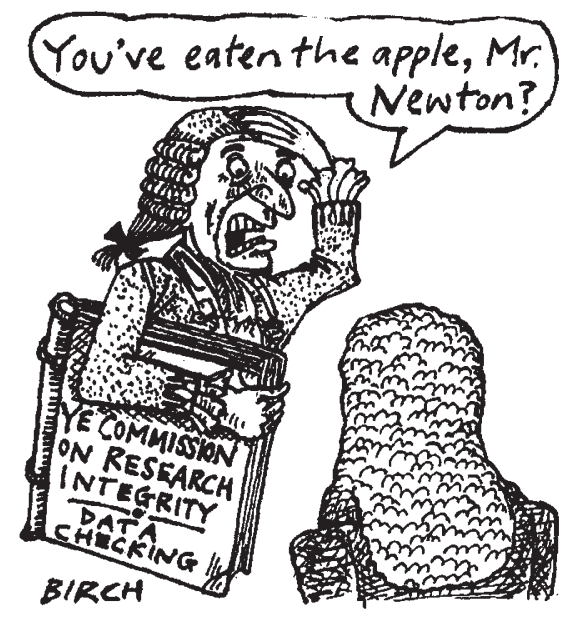

Ryan's panel will investigate the competence of the ORI and advise on definitions of misconduct, and on how allegations should be treated and whistleblowers protected. It will report to Donna Shalala, the Secretary of Health and Human Services, who has responsibility for the NIH.

Ryan, who is a professor of obstetrics, gynaecology and reproductive biology at Harvard Medical School, believes that the whistleblower issue will be tough. "Some of the things done to whistleblowers, and sometimes by distinguished scientists, are unconscionable," he says. "We know of cases where people are fired. They complain to the NIH, which insists they are reinstated, but it is a hollow victory because they are reinstated in a closet down the hall."

The commission met for the third time last week and is at the beginning of a twoyear process, but it has so far attracted little attention. "It has been treated as a nonevent, with a view of 'been there, done that'. I think this is because people don't know who Ken Ryan is," says Gunsalus.

\section{NASA scientists brace for new cuts}

Washington. Faced with a squeeze on funding for basic research, the managers of the US National Aeronautics and Space Administration (NASA)'s planetary programme last week took the unusual step of calling in a panel of outside scientists to informally advise them on where and how the research budget might be cut.

At least for the next year or two, the group was able to suggest temporary solutions that do not require cutting into the peer-reviewed 'core programmes' on which a large proportion of the US planetary science community relies for grant money. But the scientists who attended the meeting say that a larger problem still exists, namely the fact that basic research is raided whenever the space agency finds itself in a fiscal jam.

The budget for planetary research and analysis (R\&A) is around $\$ 100$ million a year, relatively little by NASA standards. But it provides grants for hundreds of researchers around the United States working on data from spacecraft missions like Voyager and Magellan. It also supports activities as diverse as instrument development and looking after the lunar samples brought back by the Apollo astronauts.

It is these non-research activities that have caused much of the problem. NASA has recently committed itself to several new projects that fall outside the traditional R\&A domain. These include participation in the Keck Observatory (see Nature 371, 189; 1994) and supplying an instrument to fly on Japan's Planet-B Mars mission in 1998. But with no extra funds allocated for the new
Ryan is, in fact, an old hand at sorting out thorny ethical issues, and has encountered both scepticism from the media and Congress, and defensiveness from the biomedical research community. For example, he is a former chairman of the National Commission for the Protection of Human Subjects in Biomedical and Behavioral Research. "We were viewed then as either whitewashers, or as revolutionaries who would kill science," says Ryan.

Misconduct is currently defined as fabrication, falsification, plagiarism and other practices. It is the last phrase that causes most contention, as it covers loosely issues such as authorship, the degree of supervision a mentor should provide for a graduate student, how long data is kept and where.

The current commission is already leaning towards a two-tier approach where federal intervention would be reserved for egregious cases and the scientific community would accept responsibility for establishing common standards of behaviour across disciplines and institutions. Helen Gavaghan

projects, they have been imposed on an R\&A account that is already strained.

Faced with the prospect of cutting research grants to accommodate the new spending, NASA R\&A managers asked for outside advice. After three days of deliberation, the panel, chaired by Jonathan Lunine of the University of Arizona, agreed on several possible solutions, which will be put to

For example, rather than introducing new research efforts (each with its own funding requirements) to address results from the Clementine lunar mission and the Shoemaker-Levy impact with Jupiter, the group proposes incorporating these subjects into existing research programmes. It also agreed to recommend that technology development within the R\&A programme be streamlined and consolidated.

These two proposals, it calculates, will be sufficient to avoid the near-term budget shortfalls. But beyond such accounting games, the scientists also had to come to terms with the new realities of NASA. Belttightening is currently taking place across the whole agency, including high-profile programmes such as the space shuttle.

Joseph Burns of Cornell University, who chairs the National Research Council's Committee on Planetary and Lunar Exploration, says planetary research is especially vulnerable to reductions in NASA funding because there are so few tenured academic positions in the field. "A lot of people are on soft money," he says. "Everybody's in pretty fragile shape."

Tony Reichardt NASA next month. 